\section{Amazônia... A ira dos poderosos. Ricardo Smith, 2016}

Por Felipe Jacinto

Universidade Federal do Pará

(fojacinto@gmail.com)

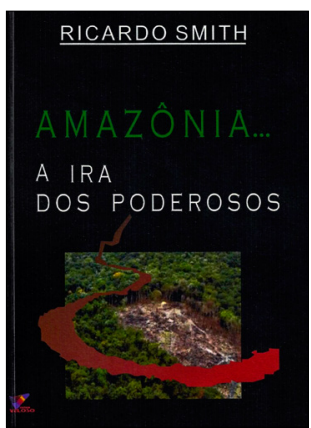

SMITH, Ricardo.

Amazônia... a ira dos poderosos. Gurupi: Editora Veloso, 2016. 170 p. ISBN: 978-8568154-17-5.

Em "Amazônia... A Ira dos Poderosos", de autoria do engenheiro Ricardo Smith, encontra-se uma produção literária repleta de problemas regionais que revela o protagonismo dos amazônidas, forjados ou legítimos, que desbravaram a selva e desenvolveram, ao longo das últimas décadas, uma rica e delicada inter-relação entre homem e natureza.

Fruto da experiência pessoal do autor na região de Marabá, onde viveu grande parte de sua juventude, a obra registra com maestria as memórias sobre os graves conflitos sociais na região entre as décadas de 1960 e 1980. Numa narrativa que incorpora e compõe a obra, Ricardo nos traz a tessitura entre a violência, o poder, e as relações homem-natureza numa terra que abrigou sonhos e foi palco de inúmeras manifestações da vida.

A obra é uma denúncia literária que demonstra os dramas de um Brasil desconhecido para muitos brasileiros, ambientada na floresta amazônica, especificamente no sudeste paraense, área que concentra historicamente intensos e graves conflitos agrários. A par dos problemas sociais da atualidade, a narrativa se ocupa de questões políticas e sociais com competência, apresentando-se de maneira leve, fluida e desafiando o leitor ao gostinho de quero mais.

Modalidade de relato pautado na realidade histórica, foge de classificações ortodoxas, trazendo um título provocador e o registro de fatos históricos no Sul-Sudeste do Pará a que o especialista em literatura amazônica, professor Dr. Paulo Jorge Martins Nunes, chamou de "narrativa-testemunhante"1.

Mesclando momentos de pura descrição literária com críticas diretas a eventos sociopolíticos da realidade, o livro vai compondo um mosaico em que as narrativas se complementam para a consolidação de uma realidade mais próxima da atual, apresentando, com detalhes, eventos e fatos que sabemos de maneira muito pontual e desconexa.

Logo de início temos o desbravamento da Amazônia e os conflitos inevitáveis com a mata, os bichos e os índios. Valorizando a fala nativa, enriquece sobremaneira a narrativa, captando a atenção do leitor de modo único.

Numa rica descrição da relação dos homens com o meio ambiente, seja desbravando a floresta desconhecida em busca de oportunidades, seja lidando com seus perigos e mistérios ou na relação com os animais domesticados e selvagens, as distintas visões dos personagens acerca dos recursos naturais e da exploração feita pelo homem revelam a visão de mundo através de um lugar até então desconhecido para os leitores.

Numa passagem, o autor, através da narrativa, dispara: "[...] acho que todo bicho que engole outro é porque tá com fome" (p. 17). Este trecho, para mim, descreve muito bem não só a relação homem-animal em questão, mas também a relação entre os empregados e patrões e a dominância que o poder e o dinheiro parecem exercer naquela região.

\footnotetext{
Nunes, Paulo Jorge Martins em aula da Disciplina 'Natureza, Agricultura e Artes', do Mestrado em Agriculturas Familiares e Desenvolvimento Sustentável, na Universidade Federal do Pará, em Belém, 17 jan. 2017.
}

JACINTO, Felipe. Amazônia... A ira dos poderosos. Ricardo Smith, 2016. Boletim do Museu Paraense Emílio Goeldi. Ciências Humanas, v. 12, n. 3, p. 969-971, set.-dez. 2017. DOI: http://dx.doi.org/10.1590/1981.81222017000300017.

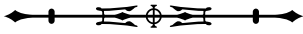


A riqueza de detalhes da narrativa de Smith é capaz de transpor o leitor para o embate com a onça, com o índio, entre os próprios homens: é a vida encarando a si mesma. Nos conflitos com os indígenas pela posse e exploração dos territórios, fica nítida a fronteira delimitando-se e impondo suas regras de convivência, onde vence o mais forte. "O índio nada respondeu, pois nada entendeu" ( $p$. 40), declaração de Smith sobre salvamento de índio ferido na selva, demonstra essa relação e o abismo cultural que se solidificou entre os homens da floresta e que, infelizmente, ainda hoje permanece quase inalterado.

Afora os perigos físicos de viver na mata, compostos por bichos e indígenas quase que imperceptíveis, o universo místico oriundo do imaginário amazônico é trazido de maneira a complementar a história com as visagens, o mapinguari, a cobra grande, os pretinhos d'água...

A saga dos imigrantes do Centro-Sul e do Nordeste na Amazônia, amazônidas forjados a ciclos de produtos florestais, relações de exploração sobre-humanas e uma íntima relação com a mata e todas as suas especificidades, que a tornavam mágica e majestosa, é apresentada ao longo da obra.

A chegada do progresso na floresta selvagem com a abertura das estradas que a integravam à nação e os problemas decorrentes desse novo fluxo que escoou nas entranhas da Amazônia desde então proporcionam a reflexão sobre distintas noções de desenvolvimento e progresso. $O$ desenvolvimento da região pautado na exploração de madeira e gado, marcado pela fragmentação da terra em um imenso mosaico de estradas e vicinais que levavam nada a lugar nenhum, privilegiava o dinheiro e o poder concentrados nas mãos de poucos, que ditavam o destino de cada um que ali vivesse.

A narrativa descreve também os percalços naturais que existiam no Rio Tocantins e os impactos causados pela Usina Hidrelétrica de Tucuruí, construída na década de 1980, quando as sociabilidades e os ritmos de vida foram profundamente alterados com a chegada deste gigante do progresso.
O avanço da fronteira com a queimada e o desmatamento da floresta virgem para a entrada do gado (de corte e leiteiro) na Amazônia, levado a cabo por homens de feição indígena, demonstra elementos da intensa miscigenação que compõe não só os caboclos e ribeirinhos amazônicos, como também todo o povo brasileiro.

O período do golpe militar de 1964 é descrito sob a perspectiva dos camponeses e cidadãos de uma Amazônia distante dos centros urbanos, mas que padeceu também aos desmandos e atrocidades que marcaram este longo período da ditadura, com a resistência de muitos setores da sociedade. O movimento de oposição no Sul do Pará, encorpado por jovens estudantes revolucionários que se mesclavam aos camponeses da mata, é especialmente narrado atestando a perseguição e captura dos "[...] paulistas [...]" (p. 59), à custa de morte e tortura de muitos inocentes pelo caminho. Era a Guerrilha do Araguaia em um território sem leis. O autor descreve brilhantemente o significado da Rodovia Transamazônica, construída durante a ditadura sob os pretextos de "[...] integrar para não entregar [...]" (p. 67) e numa "Terra sem homens para homens sem-terra [...]" (p. 67). Ela permitiu o adensamento populacional em suas margens, recebendo imenso fluxo de emigrantes nordestinos que, frequentemente, padeciam aos caprichos da floresta tropical e coabitavam numa realidade de total falta de infraestrutura que mantinha $O$ isolamento artificialmente solucionado com a chegada de mais este gigante do progresso.

O pecado dos pecados, cortar as castanheiras da floresta, marca no livro o apogeu da proliferação das madeireiras e a exploração dos recursos florestais levada aos limites do absurdo, pois a castanha era pão, era pai e mãe, era companheira da história de vida dos personagens e acabavam cortadas ou queimadas tal qual gente a pedir socorro.

Seguindo a narrativa, num fluxo de desenvolvimento desmedido começam a submergir do seio da terra as riquezas minerais: ouro, pedras preciosas, diamante, metais industriais. Agora que a floresta já não mais importava, era da terra que os homens buscavam tirar seu sustento,

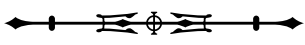


ansiando uma riqueza e um poder que comandava tudo e todos naquela região. Serra Pelada é descrita como um descontrole pessoal e coletivo, uma miragem que transformava a paisagem de serra em cava na busca pela cor dourada do enriquecimento prometido. A morte e a ganância eram companheiras do que parecia progresso e promessa de futuro naquele formigueiro humano que ceifou incontáveis vidas, esperanças e sonhos.

A ocupação desordenada nas explorações por minerais e pedras preciosas causava uma degradação sem limites do meio ambiente, bem como das noções éticas e morais da humanidade, presente ali.

A esta altura, o autor nos apresenta a figura dos pistoleiros, que passam a compor o enredo e fazer a "[...] limpeza [...]" (p. 93) onde consideravam necessário, tamanha era a quantidade de gente e situações distintas que pululavam no Sudeste do Pará. A população aumentava na mesma proporção que os índices de violência, numa terra sem leis, carente de estudo e Estado.

Agora o domínio se dava através da violência com a habitual prática de extermínios e assassinatos por encomenda, evidenciando a impotência da polícia e do Poder Público em estabelecer a mínima ordem e segurança social ali. Prevalecia a noção de fazer justiça com as próprias mãos e percebe-se a dicotomia presente na figura do pistoleiro, que, ora serve aos interesses do povo, ora serve aos interesses dos grandes latifundiários que dominavam a cena local.

Graves conflitos agrários entre fazendeiros e posseiros despertam no leitor a importância do exercício da alteridade, a capacidade de se colocar no lugar do outro. A natureza humana comparada, a equivalência das atrocidades contra os próprios homens e contra a imponente floresta, numa tentativa constante de domínio de si, do próximo e da terra em que se vive. Dessa relação delicada entre fazendeiros e posseiros surge a figura esdrúxula do grileiro, sujeito aproveitador da situação e das movimentações sociais a favor da dignidade através da terra cultivada.
A obra toma outros traços e proporções na medida em que o protagonista-narrador experimenta a prosperidade e 0 tempo passa. Os diálogos vão se tornando mais rebuscados e menos coloquiais ao passo em que a narrativa engata em fatos e ocorridos históricos recontados pelo autor, sob uma perspectiva local, rica e pulsante.

Na sequência em que trata da caça aos sindicalistas, Smith descreve que "[...] o direito, o certo, a verdade [...]" (p. 130) naquela região funcionava ao contrário e a insegurança chega até mesmo nas trilhas no interior da mata, evidenciando a relação dos homens com o poder, representado, de um lado, pelo Estado, através das figuras do delegado e da própria polícia, e, por outro, pela dominância local, com os grandes latifundiários, seus comparsas e os pistoleiros que agiam a mando deles. A impunidade geral causava revolta e descrença na população no que tangia à relação com o Estado e sua presença burocrática. Ali, literalmente, a justiça era cega.

As condições de trabalho no meio rural brasileiro são trazidas à tona com as narrativas acerca do trabalho escravo ou análogo a isso, que persiste não apenas no Pará, mas no Brasil todo como uma mazela de nossa sociedade.

Em meio a uma atmosfera de ilegalidade, desmandos, violência e impunidade, a incompreensão da natureza humana, que acaba por justificar o rastro deixado por todos os episódios narrados de violência, morte e destruição que ocorreram (e ainda ocorrem) em grande parte dos rincões do Brasil, especialmente nessa região do Sul do estado do Pará onde o autor ambienta a trama, nos define um Brasil que não passa na mídia e é muito mal desvendado pela escola, uma espécie de "[...] grito perdido no espaço" (p. 177).

A leitura da obra é indispensável para quem aprecia a boa literatura regional, bem como para pesquisadores que trabalham as diversas questões socioambientais abordadas com maestria por Ricardo Smith, e especialmente indicada para quem anseia por se aventurar com intensidade e riqueza de detalhes numa realidade amazônica desconhecida de nós, brasileiros.

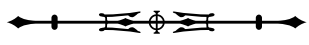

